\title{
O SERTÃOTAMBÉM SAMBA: REFLEXÕES SOBRE O SAMBA DE RODA NO DISCURSO ETNOMUSICOLÓGICO
}

\author{
Charles Exdell ${ }^{1}$
}

\begin{abstract}
Resumo: Este artigo propõe um novo conceito etnogeográfico para o samba de roda que inclui o semiárido da Bahia. Diante da ascensão do samba de roda enquanto objeto de estudo acadêmico e patrimônio do Estado, forma-se um senso comum em que este samba pertence particularmente ao Recôncavo baiano, o território por volta da Baía de Todos os Santos, e melhor reflete uma identidade baiana exclusiva às comunidades negras dessa região. A realidade do interior da Bahia - do Recôncavo até os sertões do Rio São Francisco demonstra que o samba de roda é igualmente importante às comunidades rurais multirraciais de diversas regiões do estado, contudo, cria e reflete realidades distintas. Reconhecer isso envolve enfrentar fatos incômodos: a exclusão histórica do semiárido do discurso sobre a identidade baiana, a negação da influência da cultura afrobaiana no sertão e o incontável número de 'pequenos mundos de samba' que desafiam os inventários e classificações utilizados na construção do patrimônio do estado.
\end{abstract}

Palavras-chave: Samba de roda. Baianidade. Sertão.

\section{THE SERTÃO ALSO DANCES SAMBA:THOUGHTS ON SAMBA DE RODA IN ETHNOMUSICOLOGICAL DISCOURSE}

\begin{abstract}
This article proposes a new ethno-geographic understanding of samba de roda that includes the semi-arid region of Bahia. With the ascension of samba de roda as an object of academic study and national heritage, a conventional wisdom has taken hold in which this samba is viewed as cultural heritage specific to Salvador and the Recôncavo, the region surrounding All Saint's Bay, and most reflects an Afro-Bahian identity concentrated in the black communities from this region. The reality of the Bahian interior, however, from the Recôncavo to the sertões of the San Francisco River, demonstrates that samba de roda is equally important to multiracial rural communities spread throughout the state, where it creates and reflects distinct social contexts. Recognizing this involves facing up to uncomfortable facts: the historic exclusion of Bahia's semi-arid region from discourse on Bahian identity, the denial of Afro-Bahian cultural influence in the sertão, and the acceptance of an inexpressible number of 'little worlds of samba' that defy the
\end{abstract}

${ }^{1}$ Indiana University.

Pontos de Interrogaçầo, v. 8, n. 2, jul.-dez., p. 223-238, 2018. 
inventories and classifications that state institutions often use to define heritage.

Keywords: Samba de roda. Baianidade. Sertão.

Nos últimos anos, o samba praticado na região do Recôncavo baiano, conhecido na literatura acadêmica como samba de roda ${ }^{2}$, foi reconhecido como patrimônio imaterial do Brasil e da Humanidade, e se desenvolveu entre outros para uma música de palco e de festival, enquanto símbolo celebrado da identidade baiana. Reconhecer a importância deste samba para o Recôncavo, frequentemente representado como a região geográfica principal do samba de roda e fonte da cultura matriz afro-baiana, é motivo de comemoração ${ }^{3}$. Entretanto, a atenção súbita e esmagadora a uma zona geográfica restrita, influencia a forma que se percebe e discute o samba de roda no Brasil. A veneração do samba do Recôncavo teve o efeito de reforçar uma visão periférica do samba presente nas regiões do agreste e Sertão da Bahia, impedindo uma compreensão mais aprofundada das suas raízes na cultura rural por todo o estado e ofuscando sua complexidade racial. Diante dessas inquietações, espero 1) esboçar algumas características gerais do samba no Piemonte da Diamantina, destacando diálogos intrínsecos entre os sambas aparentemente diferentes do interior da Bahia e 2) interrogar os motivos pela exclusão histórica do Sertão baiano enquanto campo de pesquisa etnomusicológico sobre o samba.

\section{O samba de roda no piemonte da diamantina}

O Piemonte da Diamantina é uma região econômica no centro-norte do Sertão baiano, onde toca-se o samba na maioria das comunidades rurais, povoados e pequenas cidades ${ }^{4}$. No Piemonte, assim como no Recôncavo, a

2 Acredito que a expressão "samba de roda", cada vez mais ubíquo enquanto termo para o samba tipicamente baiano, surge de um olhar urbano. O "de roda" representa sua diferença em relação aos sambas brasileiros mais conhecidos. Usarei o termo "samba de roda" ao longo deste trabalho para discutir o samba referente ao discurso acadêmico. Vale ressaltar, porém, que no semiárido o termo mais utilizado hoje é apenas "samba".

${ }^{3}$ Essa nova popularidade se opõe ao olhar urbano típico para o samba de roda, historicamente visto como arte primitiva (WADDEY, 1980, p. 196)

${ }^{4}$ A Bahia divide-se em 15 Regiões Econômicas. Para ver as comunidades pesquisadas pelo autor, cf. p. 6 e 7 deste artigo. 
palavra "samba" pode denotar uma dança, um tipo de performance musical e uma ocasião festiva. Pode-se tocar e dançar samba e, igualmente, ir para um samba. O repertório musical do samba envolve a alternância entre duas modalidades, a chula e o batuque, cada qual definida por uma combinação de canto, coreografia e acompanhamento instrumental, e executada em formato de uma roda ${ }^{5}$. Na roda de samba há músicos especialistas - cantadores e instrumentistas - chamados de sambadores e sambadeiras, que constituem o grupo de samba, i.e., o conjunto principal, e um coro secundário de participantes que batem palmas e, na hora do batuque, respondem aos cantos. Todos, especialistas e leigos, realizam danças variadas no centro da roda, individual e coletivamente, em momentos específicos. Enquanto ocasião festiva, o samba insere-se em devoções religiosas, encerra o trabalho no campo e motiva encontros lúdicos de amigos, familiares e grupos de pessoas, para ressaltar apenas algumas possibilidades. A sua natureza participativa e festiva dá um aspecto de "brincadeira", palavra que muitos dos seus participantes usam para descrever a reunião lúdica da roda de samba.

Se o samba é brincadeira, é também "coisa séria”. O seu significado social transcende o encontro pontual. Ser sambador ou sambadeira envolve habilidade, treino e convicção. Embora eles raramente recebam compensação monetária por fazer samba, seu prestígio enquanto músicos lhes confere amizade e respeito dentro das suas comunidades. A performance do samba afirma moralidade, códigos afetivos e crenças religiosas. Os textos poéticomusicais e as sonoridades da roda revivem memória e fundamentam a cultura acústica ${ }^{7}$ do sertão. A dança coletiva do samba possibilita o diálogo direito com divindades religiosas e a ressignificação e transformação de relações sociais. Por isso, quando o antropólogo Ari Lima (2011, p. 33) consta que o samba do Recôncavo é "uma atitude social particular, uma criação sofisticada

\footnotetext{
${ }^{5} \mathrm{~A}$ depender do local da performance e o espaço físico, a roda às vezes toma formas mais abstratas, mas continua o princípio geral dos participantes que se olham voltados para dentro.

${ }^{6}$ Expressão do Mestre Cobrinha Verde, cf. WADDEY, 1980.

${ }^{7}$ Sobre o conceito da cultura acústica, José de Sousa Miguel Lopes (2000, p. 177) observa, "Nesta cultura se recorre (como artifício de memória) ao ritmo, à música, à dança, à repetição e a redundância, às frases feitas, às fórmulas, às sentenças, aos ditados e refrãos, à retórica dos lugares-comuns e às figuras poéticas".
} 
que reflete sobre si e as condições em que se vive e sobrevive"8, vale também para as comunidades de samba do Piemonte.

O samba, sobretudo, parece articular e fundir os ritmos da vida e da música numa entidade única, o que pode ser chamado de tempo-samba, o ritmo primordial da vida rural baiano. Neste sentido, em vez de ser apenas um momento isolado que se insere pontualmente na vida dos seus praticantes, o samba é melhor compreendido como um tempo ritual que subjaz e ordena elementos distintos da vida. O conceito do samba vir "do começo dos tempos", como afirmam a grande maioria dos sambadores do Piemonte (EXDELL, 2017), é uma maneira lírica de expressar a relação entre o tempo e o samba, seu alcance expansivo na memória social coletiva e suas associações à cosmovisão sagrada dos seus praticantes. Para as comunidades concebidas dentro do tempo-samba do semiárido rural, o samba não somente existe, ele é a matriz temporal, social e moral da sua existência.

Apesar das qualidades imateriais do samba, não se deve perder de vista suas raízes nas relações de classe do interior baiano. Ao longo da história, toca-se o samba pelas mãos calejadas do camponês, trabalhador rural e operário, ora no campo ora na periferia da zona urbana. No semiárido, onde e quando o samba surge nos contextos urbanos das pequenas cidades, ele é protagonizado tipicamente por "gente da roça". O sambador na cidade muitas vezes navega uma relação tênue e conflituosa com as populações urbanas ${ }^{9}$ que, de forma crescente, rechaçam o samba, ou como marca de uma vida rural bruta e inculta, ou como uma novidade folclórica de tempos passados. Quem faz samba ainda é vaqueiro, lavrador, pedreiro, gari, pescador - herdeiros, muitas vezes, do ofício do seu trabalho e o ofício do samba. A roda de samba é a roda do moinho do engenho, a da casa de farinha e a do carro de boi. Contra o peso esmagador das 'rodas' da vida - do poder latifundiário, do legado do racismo e subordinação herdados pela escravidão, da violência estrutural comum ao mundo subalterno da zona rural da Bahia - formaram-se as rodas humanas nas quais ainda se dança, canta, brinca, desafia, une e resiste. Segundo o músico tropicalista Tom Zé no Rádio Cultura Brasil (2010), o

${ }^{8}$ Tradução minha. O texto original: “...a particular social attitude, a sophisticated creation that reflects on itself and on the conditions in which one lives and survives."

9 Deste modo, enquanto o Recôncavo ainda seja visto como lugar da "tradição" e da "raiz" do samba, seu vínculo a modo rural de viver se fragiliza pela proximidade aos grandes centros urbanos do estado. 
caboclo nordestino $^{10}$, por ser pobre, se alimentava com uma dieta muitas vezes deficiente em proteína. Foi o ritmo, junto com a farinha, que o mantinha em pé. Se o ritmo é o "Deus desidratado"ıl do Nordeste, no Sertão da Bahia, o samba é uma espécie de divindade suprema.

As rodas de samba do Piemonte são protagonizadas por gente de toda cor - negros, morenos, mulatos, mamelucos, caboclos e galegos - entre vários termos utilizados para descrever a aparência racial no interior da Bahia. As comunidades do semiárido denominadas "negras", remanescentes de quilombos fundadas por escravos fugidos e outros "indesejados" em tempos coloniais, são espalhadas pelo Sertão e preservam uma distinta territorialidade e identidade afro-brasileira. Embora essas comunidades quilombolas mantenham tradições de samba próprias, muitas vezes situadas em práticas religiosas afrocatólicas e afro-indígenas, o samba não se restringe apenas a esses contextos. Contrário à imagem do samba vigorar particularmente nas comunidades negras, ele permeia as comunidades rurais multirraciais do semiárido.

A prevalência do samba em comunidades multirraciais cria uma certa dissonância com a imagem dominante do samba de roda, muitas vezes concebida com uma cultura negra de afrodescendentes e, portanto, associada às comunidades predominantemente negras do Recôncavo baiano, região em volta da Baía de Todos os Santos, cujas economias de açúcar e tabaco, em tempos da colônia, foram erguidas por grandes contingentes de escravos africanos e seus descendentes. É comum supor que o samba se originou nos canaviais e comunidades rurais da região açucareira do Recôncavo ${ }^{12}$. Mais

\footnotetext{
${ }^{10}$ Caboclo nordestino faz referência a alguém, de fenótipo mestiço, nascido no Nordeste do Brasil, região compreendida pelos estados de Alagoas, Bahia, Ceará, Paraíba, Pernambuco, Piauí, Rio Grande do Norte e Sergipe.

${ }^{11}$ A fala na íntegra segue: "O que o nordestino comia durante quatro séculos foi uma espécie de experiência. Foi feijão e farinha e muito pouco carne do Sertão, carne do sol. Então era muito pouco proteína. E nós, e eu sou um deles né, eu sou um caboclo, aquela coisa que há uma mistura do preto, e do branco e do índio, e nós sobrevivemos, a gente ficava em pé, mesmo com tanto pouco proteína, era por causa do ritmo. Porque o ritmo no Sertão é Deus desidratado. O ritmo é capaz de manter o nordestino em pé. "

12 Carlos Sandroni e Marcia Sant'Anna sugerem que “...os sambas do sertão baiano, da Chapada Diamantina, etc., tenham sido interiorizados a partir do Recôncavo e de Salvador, para onde eram trazidos os negros escravos" (2006, p. 86). A pesquisa de Katharina Döring (2004, p. 78-79) visa uma relação mais complexa: o samba do Sertão baiano também pode ter influenciado o samba do Recôncavo, como consta Cássio Nobre (2008, p. 21). Torna-se necessário mais pesquisa sobre esse assunto. O Sertão não foi um interior vazio ou recipiente passivo da cultura do Recôncavo, se não uma região dinâmica onde elementos culturais diversos foram criados, absorvidos e reconfigurados ao longo de séculos.
} 
instrutivo do que a especulação sobre o "lugar de origem" do samba é entender sua característica fundamental enquanto tradição afro-brasileira que constitui, assim como a capoeira e o candomblé, um códice africano $a_{b e r t o}{ }^{33}$ (SEGATO, 2005) e exemplifica a distinção fundamental entre a marca da raça fenotipicamente determinada ${ }^{14}$ e a circulação e uso de uma cultura étnica afro-brasileira ${ }^{15}$ por populações de descendência racial mista. Não obstante, o estudo acadêmico busca classificar o samba da Bahia pela pressuposta de que ele tem uma identidade racial inexorável vinculada ao Recôncavo pelo legado da escravidão (LIMA, 2011, p. 33). Quando se reconhece o samba além dos limites do Recôncavo é visto, ou como restrito às comunidades negras isoladas, ou algo "menos negro" e, de alguma forma, diferente.

Em oposição à noção de que o "samba de roda" é do litoral e no agreste e semiárido da Bahia pratica-se um "samba rural", como proposta por Döring (2016, p. 70), eu sugiro que os sambas praticados na Bahia são fundamentalmente semelhantes. Apesar das suas diferenças superficiais - a variedade de apelidos regionais, instrumentos, danças, formas poéticas, e identidades étnico-raciais que constituem os pequenos mundos ${ }^{16}$ de samba da Bahia - a união entre a maioria desses sambas plurais encontra-se, sobretudo, na sua materialidade agrária subalterna e seu códice afro-brasileiro aberto às populações baianas, independentemente da sua cor. A língua franca do samba de roda é fundamental rural e permeia o litoral, agreste e semiárido baiano, porém em cada região surgem dialetos distintos. No Piemonte, o códice afrobrasileiro do samba brilha no seio das suas comunidades multirraciais.

\footnotetext{
Através destes processos, o samba de roda talvez evoluiu por um processo de troca entre o Sertão e o Recôncavo, o que resulta nas divergências e diversidade observadas hoje.

${ }^{13}$ Rita Segato usa o termo códice para se referir a relação entre a cultura étnica afro-brasileira e seu uso na sociedade brasileira. Segundo Segato, o códice do candomblé constitui um: "[...] conjunto de premissas estáveis de uma filosofia, construção de gênero e formas de organização e sociabilidade diferenciadas dentro da nação, [...] mantido pelos seus especialistas [e disponível para] toda a população e qualquer visitante que pretenda fazer uso das orientações que ele contém" (p. 3).

${ }^{14}$ Os estudos sobre raça no Brasil observam que, diferente que sua construção em outros países, sua atribuição acontece por "marca" e não por "sangue" ou "origem", e é determinado por fenótipo. Deste modo, raça é signo (SEGATO, 2005).

${ }^{15}$ Este fato não deveria diminuir sua estética afro-brasileira fundamental, presente na roda, coreografias e ritmos, cf. lyanaga (2015, p. 122) e Lima (2011).

${ }^{16}$ Expressão emprestada do pesquisador baiano Nelson de Araújo (1988).
} 
O samba de roda, de forma crescente, torna-se menos útil para as populações baianas que abandonam a vida rural, encontrando valor e autorrealização em outras culturas musicais nacionais e internacionais. $\mathrm{Na}$ medida que o samba perde importância no meio popular urbano, ganha atenção por acadêmicos e instituições culturais. Em um tempo relativamente curto, o samba de roda conquistou reconhecimento em discursos acadêmicos como símbolo de património nacional e regional e como objeto mercadológico. Deste modo, vale perguntar: diante de sua ampla e abrangente presença na região do Piemonte da Diamantina, por que raramente reconhece-se o samba como cultura intrínseca ao semiárido? Para responder a essa pergunta, é preciso refletir sobre a forma que a geografia racializada baiana e as políticas identitárias brasileiras distorcem o conhecimento construído sobre o samba, e questionar a própria ambiguidade em torno da definição e conceito do samba de roda.

Figura 1- O Piemonte da Diamantina e o Recôncavo À esquerda, a área geográfica percorrida pelo autor durante sua pesquisa. À direita, Salvador e o Recôncavo.

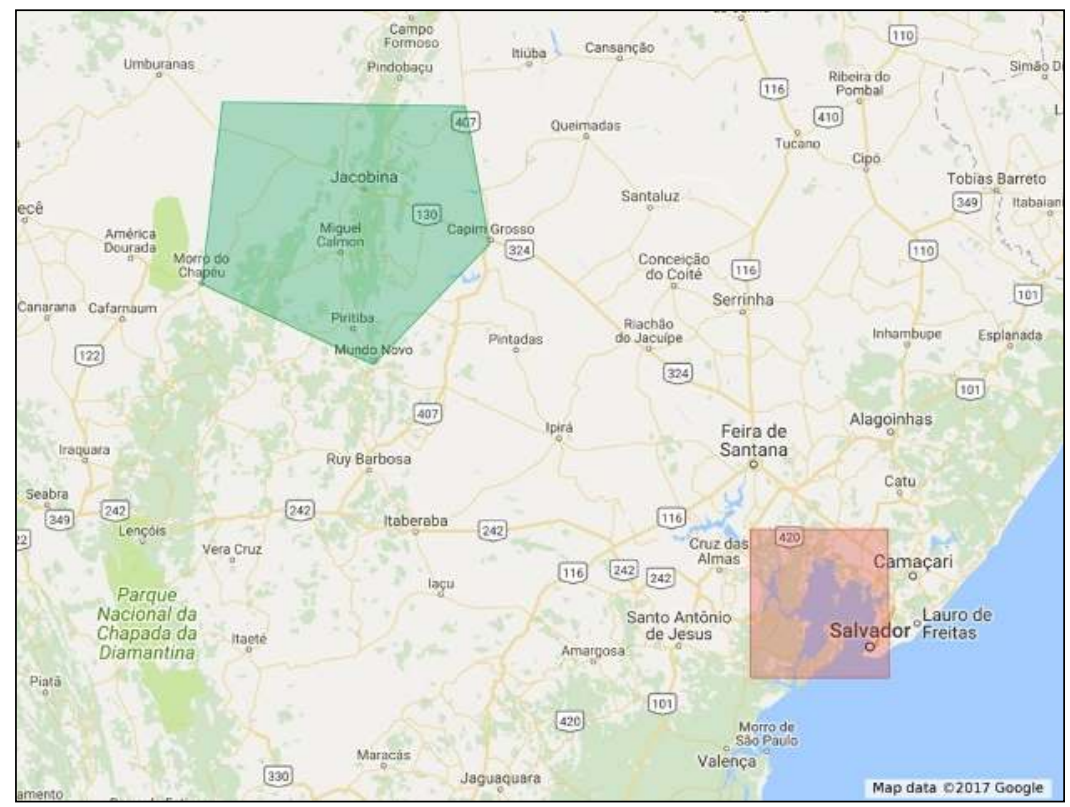


Figura 2-Grupos de samba do Piemonte da Diamantina Os pontos representam grupos de samba ativos no Piemonte da Diamantina, conhecidos pelo autor entre 2007 e 2017. Há, certamente, muitos grupos e comunidades não constados no mapa.

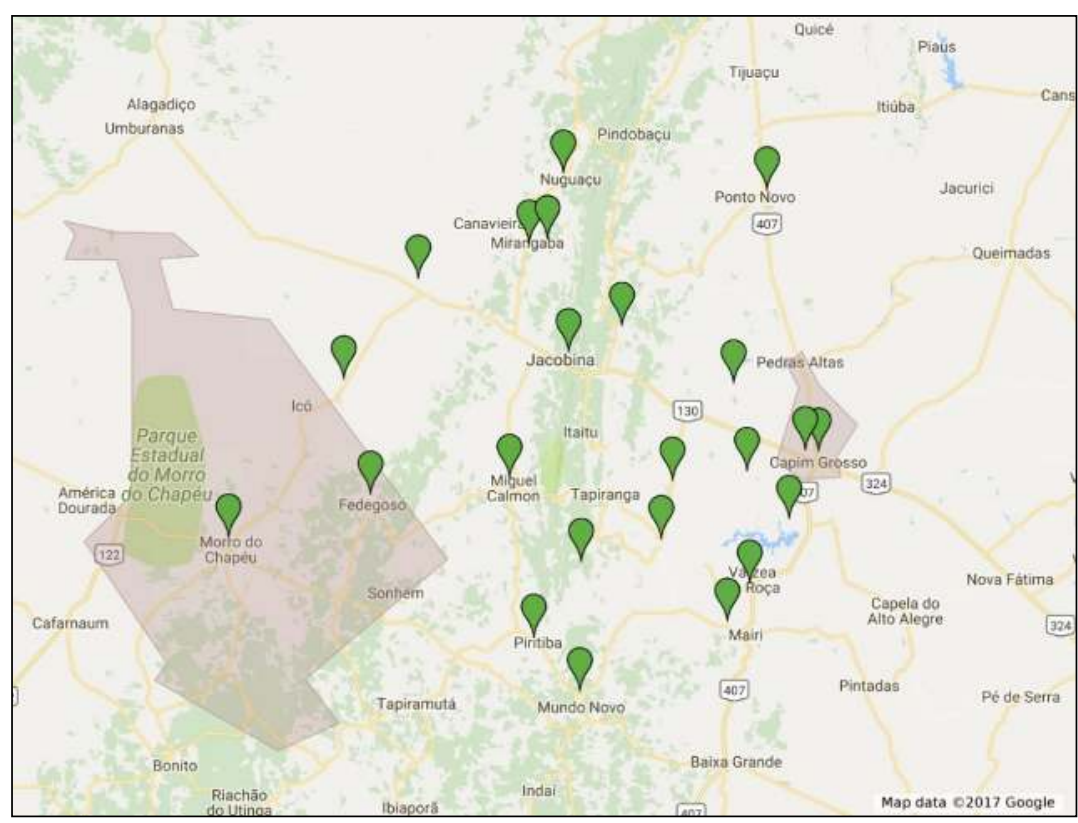

\section{A historicidade do samba de roda e a geografia racializada baiana}

Os etnomusicólogos ainda não entraram em acordo sobre uma definição universal de samba de roda. As tentativas mais citadas listam aspectos salientes da sua performance, i.e., seus cantos responsoriais, coreografias, textos poéticos, ritmos e formação circular, assim como a ubiquidade e mutabilidade da sua performance em diversos eventos rituais (ver IYANAGA, 2015; SANDRONI, 2010). Ao mesmo tempo, suas características regionais variadas inspiram definições mais gerais. Ordep Serra chama o samba de roda de um "pequeno laboratório de criação musical" (2009, p. 120) e Katharina Döring o descreve como "o desejo individual e coletivo de se reunir, tocar, cantar e dançar” (2016a, p. 72). Há consenso, porém, na percepção do seu centro enunciativo ser localizado nas comunidades afrodescendentes do Recôncavo baiano. O que significa esta caracterização etnogeográfica em termos do discurso sobre samba de roda e sua apresentação a um público nacional e internacional? É difícil compreender o fenômeno do samba no 
Brasil sem reconhecer sua relação com a construção hegemônica de noções de raça e a formulação de identidades nacional e regional ao longo da história brasileira. Há três momentos chaves que ajudam a entender a construção do lugar de samba de roda dentro do discurso identitário brasileiro e o peso dos marcadores etnogeográficos "Recôncavo" e "afrodescendente".

Durante o século XIX e no início do século XX, a palavra "samba" aparece em fontes escritas junto com "batuque" e "batucada", muitas vezes utilizada pejorativamente para descrever encontros musicais de negros e mestiços. Para os autores destes documentos escritos, os sambas ritmados e barulhentos representaram uma ofensa à autoridade e as boas sensibilidades musicais europeias (SANTOS, 1997). Durante o mesmo período, intelectuais como Nina Rodrigues, Oliveira Viana e Sílvio Romero postularam que o progresso da nação incipiente só poderia ser assegurado através da arianização da população brasileira (MUNANGA, 2008) e a eliminação de African survivals - traços negativos associados à cultura de afrobrasileiros como o alcoolismo, sensualidade, violência, homossexualidade e samba (LIMA, 2011, p. 28).

Com a chegada de imigrantes do Norte do país no Rio de Janeiro no início do século XX, entre eles contingentes de baianos, um tipo de samba também se estabeleceu nos morros e bairros populares do Rio de Janeiro. A partir da década dos anos 20, o "samba do morro" se difundiu por diversas camadas sociais da capital brasileira, auxiliado pelas inovações tecnológicas da época - a rádio e o disco (PARANHOS, 2010). Nos anos 30, sua popularidade logo se alastrou pelo Brasil urbano e parecia afirmar a ideia de democracia racial advogada por Gilberto Freyre e Mário de Andrade, na qual a mestiçagem foi redefinida como a essência do ser brasileiro e uma força social positiva (MUNANGA, 2008). Em vez de excluir e eliminar as populações de cor da sociedade brasileira, Freyre vislumbrou a sua integração e a dissolução de identidades étnicas em prol de uma única cultura nacional. Deste modo, o samba tornou-se símbolo visceral das possibilidades da mestiçagem e uma identidade nacional unificadora (PARANHOS, 2010). Hoje o samba do Rio de Janeiro, também conhecido como samba carioca, continua sendo sinônimo para o "samba brasileiro".

O samba no discurso identitário brasileiro surge novamente quando um samba regional, diferente do estilo carioca, foi pesquisado no Recôncavo baiano pelo norte-americano Ralph Cole Waddey $(1980,1981)$ no fim da década 
dos anos 70. Peculiar ao interior da Bahia, a música pesquisada por Waddey no Recôncavo pareceu referenciar um modo antigo de fazer samba, com sua formação circular e cantos responsoriais. Ela tornou-se enfoque de pesquisa acadêmica nas décadas seguintes e foi declarado patrimônio nacional pelo IPHAN (Instituto do Patrimônio Histórico e Artístico Nacional) e patrimônio oral e imaterial da humanidade pela UNESCO. Este samba seria conhecido por todo o Brasil como samba de roda: ícone da identidade cultural baiana e, sobretudo, patrimônio das comunidades rurais e pequenas cidades majoritariamente negras do Recôncavo baiano.

Se o samba carioca serviu para promover ideias de nação, modernidade e integração racial, o samba de roda é marcado pelo seu caráter regional, evocando uma identidade particularmente baiana, a baianidade, definida por Claudia Vasconcelos (2011) como:

[...] um conjunto de referências identitárias acerca dos modos de construção e de percepção do pertencimento à Bahia. Bahia esta que, para os não-baianos e para muitos habitantes do interior do estado, compreende apenas a cidade de Salvador e o Recôncavo, não coincidindo, portanto com os limites geopolíticos do estado da Bahia (p. 21).

A baianidade surge nos anos 40 como reação a um discurso modernizante brasileiro do Rio de Janeiro e São Paulo que apresentava o ideal da democracia racial, mas enxergava o futuro do país na indústria e modelo racial dos estados com maior descendência europeia concentrados no sul do país. Em resposta, setores da sociedade baiana - intelectuais, artistas e donos da imprensa - desenvolveram seu próprio discurso identitário que, segundo Scott Ickes (2011), formou a estética de uma identidade regional baiana em que os afro-baianos e a cultura afro-baiana foram revestidas de grande importância. Os elementos constituintes desta identidade - a festividade, o candomblé, a capoeira e a musicalidade - em pouco tempo após o fim da segunda guerra mundial, tornaram-se sinônimos à "Bahia" (2011, p. 442) e consolidaram uma imagem do estado baseada nas culturas da sua capital e litoral. Por outro lado, foram ignorados os grandes territórios do interior do estado (o agreste e o Sertão), localizados para além das regiões onde as imagens formativas da baianidade foram feitas e circuladas. 
A inscrição do samba de roda no Livro do Registro das Formas de Expressão do IPHAN, em 2004, e sua subsequente decretação como Obraprima do Patrimônio Oral e Imaterial da Humanidade pela UNESO em 2005, engessou o essencialismo geográfico e cultural da baianidade no discurso sobre o samba de roda. O momento também sinalizou um passo decisivo na materialização do samba de roda enquanto objeto cultural - fundamental à difusão da sua imagem etnogeográfica. Produto dessa patrimonialização, o dossiê Samba de Roda do Recôncavo Baiano do IPHAN, lançado em 2007 e elaborado por meio de uma equipe de acadêmicos, proclama o vínculo especial entre o samba de roda e o Recôncavo. O dossiê declara: "O samba de roda é uma manifestação musical, coreográfica, poética e festiva, presente em todo o estado da Bahia, mas muito particularmente na região do Recôncavo" (SANDRONI; SANT"ANNA, p. 23) - a região responsável pelas "principais referências culturais e artísticas e, por assim dizer, pelo etos atribuído, fora e dentro do Estado, ao povo baiano" (ibid., p. 17). O samba de roda, então, serve para afirmar essa importância. Ao abordar a identidade etnicorracial do samba de roda, o dossiê ressalta:

O samba de roda, desde antigos relatos, traz como suporte determinante tradições culturais transmitidas por africanos escravizados no Estado da Bahia. [...] o samba de roda foi e é essencialmente uma forma de expressão de brasileiros afrodescendentes, que se reconhecem como tais (ibid., p. 24).

Apesar de algumas ressalvas no fim do texto ${ }^{17}$, o título do dossiê fala por si: Samba de Roda do Recôncavo Baiano. Nos anos anteriores à publicação do dossiê, o Recôncavo também foi contemplado com o museu Casa do Samba e a Associação de Sambadores e Sambadeiras (ASSEBA), localizados em Santo Amaro, uma cidade colonial histórica do Recôncavo. Logo depois foi criado o Plano de Salvaguarda com o intuito de fomentar o interesse no samba de roda e fortalecer o diálogo entre os grupos ativos do interior ${ }^{18}$, porém sem

\footnotetext{
${ }^{17}$ No final do dossiê aparece este parágrafo: “Como foi dito no início, o samba de roda é encontrado em todo o estado. Presume-se que os sambas do sertão da Bahia, da Chapada Diamantina etc., tenham sido interiorizados a partir do Recôncavo e de Salvador, para onde eram trazidos os negros escravizados. No entanto, após tanto tempo, essas outras regiões devem ter desenvolvido modalidades específicas de samba de roda" (p. 86).

18 Para uma ampla discussão sobre os efeitos da patrimonialização do samba, cf. LIMA, 2011 ou SANDRONI, 2010.
} 
apresentar um plano para a integração de grupos mais distantes. O novo patrimônio nacional, agora sob custódia das instituições estaduais e federais de cultura, e com uma imagem proposta para o público centrado no Recôncavo, se tornaria o símbolo reinante do samba de roda.

O lançamento do dossiê estimulou uma nova onda de pesquisas acadêmicas sobre o samba de roda. Embora muitas dessas pesquisas abordassem o samba do Recôncavo de maneira elucidativa, com foco etnomusicológico na viola machete (NOBRE, 2008), os cantadores de chula (DÖRING, 2016a), os efeitos da patrimonialização do samba de roda sobre as comunidades do Recôncavo (LIMA, 2011), e a relação entre o samba e as práticas afrocatólicas (IYANAGA, 2015, 2010), entre diversos temas, o enfoque acadêmico concentrou-se de modo quase exclusivo na região do Recôncavo baiano. Reforçado pelo coro de acadêmicos, "o samba de roda do Recôncavo baiano" seria divulgado na imprensa e as verdades do dossiê reproduzidos pelas manchetes do Brasil ${ }^{19}$. Porém, referente à possibilidade de outros sambas também integrais às identidades baianas além do Recôncavo, a força cumulativa dessas vozes poderosas formalizou o senso comum do samba de roda dentro da matriz ideológica da baianidade. Algumas interrogações sobre o alcance do samba além do Recôncavo, presentes nos primeiros artigos de Waddey $(1980,1981)$ e pautado periodicamente por algumas vozes solitárias (DÖRING, 2016a, 2014), a grosso modo, receberam pouca atenção etnográfica.

A baianidade, entretanto, não pode ser responsabilizada exclusivamente pelas lacunas no discurso acadêmico. A identidade etnicorracial é negociada entre regiões e grupos (MUNANGA, 2008). Oposto à geografia racializada da baianidade, o semiárido baiano - a maior área geográfica do estado constituída por 265 municípios - representa o lugar do "outro" ou do "não-baiano". A concepção popular da sua paisagem musical abrange forró, toadas, aboios e ranchos, mas raramente inclui o samba. No seu livro Terreiros de Samba-Chula (2015), o músico e historiador amador Roque Ferreira apresenta uma concepção musical típica do Sertão quando decreta:

Negro retinto o sertão só conheceu de gotejo, um e outro adquirido em leilão de fugido ou comprado no mercado

${ }^{19} \mathrm{Cf}$. , por exemplo, o site http://bahia.com.br/viverbahia/cultura/samba-de-roda/. 
negreiro formal. Esses poucos africanos encontravam serventia no trabalho doméstico e no plantio de feijão, arroz, mandioca, milho, algodão e alguma cana. No vaquejado vigorou uma gênese itinerante de cafuzo, mameluco e algum cabra e mulato [...] A música no sertão foi o aboio, que o árabe-islâmico ensinou ao pastor espanhol. Esta cantilena moura, toada lamentosa e de acentuadas interjeições até o chamamento langoroso, fez do coração do vaqueiro pátria e entrou para os ranchos e bumbas... A música do Recôncavo foi o batuque transformado em Samba-Chula [...] (p. 33)

As dicotomias Recôncavo-Sertão, Negro-Mestiço e Samba-Aboio são simultaneamente geográficas, raciais e culturais, porém a palavra chave para compreender a constatação de Ferreira é sertanidade a gama de características sócio-históricas, culturais e raciais atribuídas ao Sertão.

O Sertão associou-se fortemente com o clima e a ecologia da região nordestina brasileira, seu sentido sinônimo para seca e caatinga. A paisagem do Sertão, nessa concepção, é construída como lugar longínquo, despovoado e de difícil acesso (FERREIRA, 2004, p. 30). Esse Sertão também manifesta o poder de moldar seus próprios habitantes, conhecido como sertanejos, através de "forças telúricas" (BLAKE, 2011). Devido às condições climáticas, o sertanejo torna-se um agricultor resistente e bruto, condenado à penúria perpétua. No contexto do movimento para a arianização do Brasil no início do século XX, o Sertão - com sua imagem de terra-sem-lei, populações subalternas negras e indígenas, desigualdade social e decadência econômica - teria sua marginalização racializada. As características raciais dos sertanejos se tornariam a causa do seu suposto atraso e pobreza. No cerne do debate sobre identidade nacional durante o século XX, a construção do caráter racial do sertanejo é central à luta identitária da região.

A partir dos anos 20, políticos e intelectuais do Norte do país, sentindo-se excluídos do discurso sobre nação, propuseram a unificação sob a bandeira de uma nova região nordestina, o Nordeste, e a ressignificação da cultural rural dos seus habitantes. O arquétipo deste brasileiro nordestino seria construído pela reimaginação do sertanejo: um agricultor forte, resistente e sabido que supera as dificuldades do clima e apresenta uma feição racial de um mameluco ou caboclo - uma mistura entre sangue europeu e indígena - bem alinhada às ideias de mestiçagem predominantes da época e, portanto, símbolo do verdadeiro brasileiro. Sem surpresa, a proliferação do sertanejo como ícone da alma brasileira foi predicada na negação da sua 
ancestralidade negra, a minimização da amplitude da escravidão no semiárido, a negação da soberania migratória de populações afro-brasileiras e as muitas comunidades quilombolas, e a rejeição da influência cultural afrobrasileira através da mestiçagem. A imagem do sertanejo mestiço seria veiculada ao longo do século XX por intelectuais, escritores e artistas ${ }^{20}$. Embora não apagasse a duradoura imagem do sertanejo como um agricultor atrasado e inculto (VASCONCELOS, 2007, p. 48), a ideia do sertanejo nordestino teria enorme peso cultural no Brasil, passando a definir a sertanidade, ofuscar a complexidade racial da região conhecida como Sertão e influenciar a auto-concepção dos seus próprios habitantes.

Uma investigação superficial do samba no Piemonte da Diamantina desmente muitas dessas caracterizações. Além das construções da baianidade e sertanidade, o interior da Bahia possui diversas comunidades quilombolas ${ }^{21}$, comunidades rurais multirraciais e a cultura afro-baiana, exemplificada pela profusão de samba de roda. Deste modo, ao tentar definir samba de roda independente da geografia racializada da Bahia, ele poderia ser caracterizado como a música afro-brasileira que melhor fundamenta e expressa a experiência rural baiano. Reconhecer isso envolve enfrentar fatos incômodos: a exclusão histórica do semiárido do discurso acadêmico sobre a identidade baiana, a negação da influência e difusão das culturas afro-baianas no Sertão, e o inexpressável número de pequenos mundos de samba que desafiam os inventários e classificações utilizados na construção do patrimônio nacional brasileiro.

\section{Referências}

ARAÚJO, N. de. Pequenos mundos: um panorama da cultura popular da Bahia. Tomo II. Salvador: Universidade Federal da Bahia, 1988.

BLAKE, S.E. The vigorous core of our nationality: race and regional identity in northeastern Brazil. University of Pittsburg Press, 2011.

\footnotetext{
${ }^{20}$ Luiz Gonzaga, Graciliano Ramos, Guimarães Rosa, Patativa do Assaré, entre outros, cf. VASCONCELOS, 2007, p. 54.

${ }^{21}$ Para uma lista das comunidades quilombolas certificadas e outras com processos abertos na Bahia, cf. http://www.palmares.gov.br/.
} 
DÖRING, K. Cantador do chula: o samba antigo do recôncavo. Salvador: Pinaúna Editora, 2016a.

DÖRING, K. Cartilha do samba chula. Salvador, 2016b.

DÖRING, K. Raízes do samba de tocos: o samba de roda do recôncavo e o samba rural do agreste. In: Tambores e Batuques - Circuito 2013/2014 (Sonora Brasil). Rio de Janeiro: Sesc, Departamento Nacional, 2013. p. 38-49.

DÖRING, K. Samba na Bahia: tradição pouco conhecida. Ictus, Salvador: v. 5, p. 69-92, 2004.

EXDELL, C. Violeiro de samba: retratos do samba de roda no Sertão baiano. 164 f. il. 2017. Dissertação (Mestrado) - Escola de Música, Universidade Federal da Bahia, Salvador, 2017.

FERREIRA, J.P. Um longe perto: os segredos do sertão da terra. Légua \& meia: revista de literatura e diversidade cultural, Feira de Santana, v. 3, n. 2, p. 25-39, 2004.

FERREIRA, R. Terreiros de samba-chula. Salvador: Fast Design, 2015.

FUNDAÇÃO CULTURAL PALMARES. Comunidades remanescentes de quilombolos (CRQ's). Disponível em: http://www.palmares.gov.br/comunidades-remanescentes-de-quilomboscrqs. Acesso em: 18 de ago. 2017.

ICKES, S. Salvador's Modernizador Cultural: Odorico Tavares and the Aesthetics of Baianidade, 1945-1955. The Americas, v. 69, n. 4, p. 437-466, 2003.

IYANAGA, M. O samba de caruru da Bahia: tradição pouco conhecida. Ictus, Salvador: PPGMUS/UFBA, vol. 11, n. 2, p. 120-150, 2010.

IYANAGA, M. Why Saints Love Samba: A Historical Perspective on Black Agency and The Rearticulation of Catholicism in Bahia, Brazil. Black Music Research Journal, Illinois, v. 35, n. 1, 2015. p. 119-147.

LIMA, A. Tradition, History and Spiral of Time in the Samba de Roda of Bahia. In: TILLIS, A.D. (Ed.) (Re)considering blackness in contemporary AfroBrazilian (con)texts. New York: Peter Lang, 2011. p. 27-45.

LOPES, J.S. M. O lugar da cultura acústica moçambicana numa antropologia dos sentidos. In: VI Congresso Luso-Afro-Brasileiro de Ciências Sociais, 2002, Porto. As Ciências Sociais nos Espaços da Língua Portuguesa: Balanços e desafios. Porto: Faculdade de Letras, 2000. v. 2, p. 177-187. 
MUNANGA, K. Rediscutindo a mestiçagem no Brasil: identidade nacional versus identidade negra. Belo Horizonte: Autêntica, 2008.

NOBRE, C.L. Viola nos sambas do Recôncavo baiano. 2008. 190 f. Dissertação (Mestrado) - Escola de Música, Universidade Federal da Bahia, Salvador, 2008.

PARANHOS, A. Percursos sociais do samba: de símbolo étnico ao samba de todas as cores. In: GOMBERG, E; MANDARINO, A.C. de S. Racismo: olhares plurais. Salvador: Edufba, 2010.

REIS, J. J. Tambores e temores: a festa negra na Bahia na primeira metade do século XIX. In: CUNHA, M. C. P. (Org.). Carnavais e outras f(r)estas. Campinas: Ed. Unicamp, 2005. p. 101-147.

SANDRONI, C. Samba de roda, patrimônio imaterial da humanidade. Estudos avançados, v. 24, n. 69, p. 373-388, 2010.

SANDRONI, C.; SANT'ANNA, M. (Org.) Samba de roda no Recôncavo baiano. Brasília: Iphan, 2007.

SANTOS, J. Divertimentos estrondosos: batuques e sambas no século XIX. In: SANSONE, L; SANTOS, J. (Org.) Ritmos em trânsito: sócio-antropologia da música baiana. São Paul: Dynamis, 1997.

SEGATO, R.L. Raça é signo. In: Série Antropologia, Brasília: n. 372, 2005. p. 1-16.

SERRA, O. Rumores de festa: o sagrado e o profano na Bahia. 2.ed. Salvador: EDUFBA, 2009.

VASCONCELOS, C. Ser-tão baiano: o lugar da sertanidade na configuração da identidade baiana. 2007. 115 f. Dissertação (Mestrado) Faculdade de Comunicação, Universide Federal da Bahia, Salvador, 2007.

WADDEY, R. 'Viola de Samba' and 'Samba de Viola' in the Recôncavo of Bahia (Brazil). Latin American Music Review, v. 1, n. 2, p. 196-212, 1980.

WADDEY, R. 'Viola de Samba' and 'Samba de Viola' in the Reconcavo of Bahia (Brazil) Part II: Samba de Viola. Latin American Music Review, v. 2, n. 2, p. 252279, 1981.

Recebido em: 31/10/2018

Aprovado em: 04/12/2018 